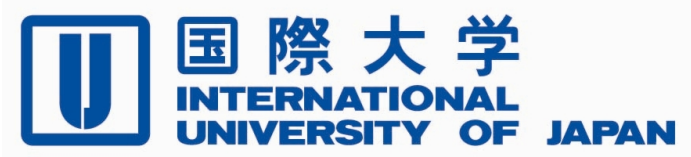

Economics \& Management Series $\quad$ EMS-2014-02

\title{
An Estimated Search and Matching Model of the Japanese Labor Market
}

\author{
Ching-Yang Lin \\ International University of Japan
}

Hiroaki Miyamoto
International University of Japan

February 2014

IUJ Research Institute

International University of Japan

These working papers are preliminary research documents published by the IUJ research institute. To facilitate prompt distribution, they have not been formally reviewed and edited. They are circulated in order to stimulate discussion and critical comment and may be revised. The views and interpretations expressed in these papers are those of the author(s). It is expected that the working papers will be published in some other form. 


\title{
An Estimated Search and Matching Model of the Japanese Labor Market*
}

\author{
Ching-Yang Lin \\ International University of Japan \\ Hiroaki Miyamoto $^{+}$ \\ International University of Japan
}

February 6, 2014

\begin{abstract}
This paper studies how well a simple search and matching model can describe aggregate Japanese labor market dynamics in a full information setting. We develop a discrete-time search and matching model with a convex vacancy posting cost and three shocks: productivity, separation, and markup shocks. We use the model as a data-generating process for our empirical analysis and estimate it by using Bayesian methods. The model is successful in replicating the behavior of unemployment and vacancies in Japan. However, we also find that the success of the model relies on shock processes that are not empirically plausible.
\end{abstract}

JEL Classification: C11; C51; E24; J64

Keywords: Search and matching model; Unemployment; Bayesian Estimation; Japanese labor market

${ }^{*}$ We are grateful to the editor, Shin-ichi Fukuda, and anonymous referees for very helpful comments and suggestions. We are also grateful to Ryoichi Imai and Yuya Takahashi and seminar participants at the Search Theory Workshop at Kansai University for their invaluable comments and suggestions. All remaining errors are ours. Part of this research is supported by the Grants-in-Aid for Young Scientists of the Japan Society for the Promotion of Science (Kakenhi No. 23730197 and No. 24730179).

${ }^{\dagger}$ Corresponding Address: Hiroaki Miyamoto, hmiyamot@iuj.ac.jp, 777 Kokusai-cho, Minami Uonuma-shi, Niigata 949-7277 JAPAN, TEL., +81-25-779-1464, FAX., +81-25-779-1187. This paper was written during my stay in the Center for International Research on the Japanese Economy (CIRJE) at the University of Tokyo. I am very grateful for their hospitality. 


\section{Introduction}

The search and matching model has been often used for studying aggregate labor markets. However, the model has recently criticized for its inability to account for the cyclical properties of the U.S. labor market. Shimer (2005) demonstrates that the model cannot generate the observed unemployment and vacancy fluctuations in response to productivity shocks of reasonable size. This failure of the model has come to be known as the "Shimer puzzle". ${ }^{1}$ Recently, a number of papers study whether the Shimer puzzle holds for the Japanese labor market (Esteban-Pretel et al., 2011; Miyamoto, 2011; Tawara, 2011). ${ }^{2}$ In order to examine whether the model is able to capture the data, these studies use the calibration method and concentrate on the model's ability to replicate a few key statistics. One issue with such an approach is that information on some parameters in the model is difficult to pin down. ${ }^{3}$ Furthermore, it is hard to study the quantitative implications of the entire model.

The purpose of the paper is to study how well the search and matching model can describe aggregate Japanese labor market dynamics in a full information setting. We treat our model as a data-generating process for aggregate labor market variables, and estimate a set of key parameters that drive cyclical labor market dynamics. We also examine the source and size of fluctuations and evaluate the ability of the search and matching model to replicate cyclical behaviors of the Japanese labor market.

We develop a simple discrete-time search and matching model with a convex vacancy posting cost and three shocks: productivity, separation, and markup shocks. We incorporate the convex vacancy posting cost since it is known that the curvature of the vacancy posting cost affects the quantitative property of the search and matching model (Fujita and Ramey, 2007; Yahiv, 2006). Incorporating a persistent shock to the separation rate is motivated by the fact that the unemployment inflow rate significantly contributes the unemployment dynamics in Japan (Miyamoto, 2011; Lin and Miyamoto, 2012) ${ }^{4}$. Be-

\footnotetext{
${ }^{1}$ In the literature, many solutions have been proposed to solve this problem. See Hornstein, Krusell, and Violante (2005) and Nagypál and Mortensen (2007) for surveys.

${ }^{2}$ While the methodology to answer the question is different among these studies, all papers reach the same conclusion that the Shimer puzzle holds for the Japanese economy.

${ }^{3}$ As Lubik (2009) mentioned, calibrating the search and matching model tends to be problematic since some of the model parameters, such as the flow value of unemployment and the worker's bargaining power, are difficult to pin down.

${ }^{4}$ Recent empirical studies demonstrate that both unemployment inflow and outflow rates significantly contribute the unemployment dynamics in Japan. Miyamoto (2011) and Lin and Miyamoto (2012) examine the relative importance of inflow and outflow rates for fluctuations in unemployment, and find
} 
side these two extensions, we also introduce a markup shock into our model, since recent studies find that markup shocks largely accounts for the labor market dynamics.

We first ignore the markup shock and estimate the model using Bayesian methods for data on unemployment and vacancies in Japan. While model parameters are chosen to match selected data moments in calibration methods, they are selected by taking into account all moments of the data in our structural estimation. ${ }^{5}$ The structural estimation of the full model allows us to examine the ability of the model as a plausible description of labor market dynamics. We find that parameters are tightly estimated and shifted away from their priors, indicating the data are informative and parameters are identified. In order to match the data, the model estimates requires a high replacement ratio and a low worker's bargaining power. These parameter estimates are consistent with what Hagedorn and Manovskii (2008) suggest in their calibration.

We also find that the model is capable of replicating the behavior of unemployment and vacancies remarkably well. Specifically, the model replicates the volatility of unemployment and vacancies and a negative relationship between them (the Beveridge curve) in the data. Given that the model parameters are estimated to match the data, in general, this is not surprising. However, it is well known that search and matching models cannot generate the observed negative relationship between unemployment and vacancies when the separation rate is counter-cyclically moving in the model (Fujita and Ramey, 2012). Thus, our finding is important since our model can replicate the Beveridge curve even when the separation rate moves counter-cyclically.

We find that the relative success of the model in replicating the cyclical behavior of the labor market relies on shock processes that are not empirically plausible. The volatility of labor productivity process inferred through the estimation process is too large relative to that of the observed labor productivity series. On the other hand, the volatility of separation process in the estimated model is too small relative to that of the

approximately a 50:50 inflow/outflow split to unemployment variation in Japan.

${ }^{5}$ Instead of using calibration methods, the advantage of using estimation in the analysis of the business cycle is as follows. In calibrating business cycle models, researchers use a set of parameters that have been estimated in other research works separated from their present research. Given the calibrated parameters, the model may or may not match the data, and researchers want to know what makes the model successful or unsuccessful. In order to diagnose a failure of the model, researchers change calibrated parameters and repeat the exercise with no explicit criterion to stop the trials. Although direct estimation of parameters is involved with massive computational tasks, the procedure proposes a posterior set of parameters and variables that are most consistent with the data of the real economy. We can also obtain alternative estimates by trying a limited number of combinations of observable variables and parameters. 
observed separation rate series. Under these shocks, volatilities of unemployment and vacancies relative to the volatility of output are too small in the estimated model. This is another manifestation of the Shimer puzzle.

We also explore the implication of wage rigidity and the markup shock. We find that a sluggish wage determination mechanism and the markup shock help improving the ability of the model to fit the data. However, the model still faces the problem that the results of the model rely on atypical shock processes that are not empirically plausible. This finding casts doubt on the viability of the search and matching model to provide a theory of labor market dynamics, as suggested by Lubik (2009).

This study is related to the recent literature on the quantitative implications of the search and matching model. A number of papers study the ability of the search and matching model to account for the cyclical properties of the Japanese labor market (Esteban-Pretel et al., 2011; Miyamoto, 2011; Tawara, 2011). While they use the calibration methods and concentrate on the model's ability to replicate a few key statistics, we rather study the quantitative implications of the entire search and matching model by using Bayesian estimation. This paper reaches the conclusion that the Shimer puzzle holds for the Japanese economy as previous studies obtained. With our best knowledge, this is the first structural empirical study of the search and matching model for Japan.

This paper is closely related to Lubik $(2009,2011)$. He estimates a search and matching model using Bayesian methods for the U.S. data and the Hong-Kong data. He demonstrates that basically a search and matching model is successful in describing the US and Hong-Kong labor markets well. However, Lubik (2009) shows that the success of the model relies on atypical shock process that may not have economic justification. By using the Japanese data, we show that the search and matching model succeeds to explain the dynamics of unemployment and vacancies well. However, we show that the model still fails to generate the observed volatilities in labor market variables relative to output. This finding complements the results of Lubik $(2009,2011)$.

Our paper is also related to the literature of the application of a search and matching model to the Japanese economy. In order to explain the low rates of unemployment, job creation and destruction in Japan, Miyamoto and Shirai (2006) develop a search and matching model with firm specific skill training. Esteban-Pretel and Fujimoto (2012) develop a life-cycle search and matching model and demonstrate that their model can capture the observed life-cycle properties of the Japanese labor market. They also conduct several experiments related to the Japanese economy. Our paper differs from these 
studies by focusing on the cyclical properties of the Japanese labor market. ${ }^{6}$

The remainder of the paper is organized as follows. Section 2 presents salient features of the Japanese labor market over the business-cycle. Section 3 develops a simple discrete-time search and matching model with convex vacancy posting costs and three shocks: productivity, separation, and markup shocks. We use this model as a datagenerating process for our empirical analysis. In Section 4, we discuss the data and priors used for our estimation. We then present the estimation results and discuss the model's ability to fit the data and sources of labor market fluctuations. In Section 5, we examine the quantitative performance of the search model by changing model specification and choices of observables and shocks. Section 6 concludes.

\section{Cyclical properties of the Japanese labor market}

We now present the cyclical characteristics of the Japanese labor market. We are mainly interested in cyclical behavior of labor productivity $A$, and five labor market variables: the unemployment rate $u$, the vacancy rate $v$, the job finding rate $f$, the separation rate $s$, and the real wage $w$.

Labor productivity is measured as real output per employed workers. The output comes from the National Income and Product Accounts, while employment is obtained from the Labour Force Survey (LFS) conducted by the Statistics Bureau and the DirectorGeneral for Policy Planning. We obtain the unemployment rate from the LFS. The vacancy rate is obtained from the monthly Report on Employment Service (Shokugyo Antei Gyomu Tokei) conducted by the Ministry of Health, Labour and Welfare (MHLW). Following Miyamoto (2011) and Lin and Miyamoto (2012), we construct the job finding and separation rates from the LFS. ${ }^{7}$ Real wages are taken from Monthly Labour Survey (MLS) conducted by the MHLW. We are also interested in the cyclical behavior of output $y$. The output series is real gross domestic product in per capita term. All data are

\footnotetext{
${ }^{6}$ Esteban-Pretel and Fujimoto (2012) also suggest that the Japanese labor market has been experiencing considerable structural changes over the recent decades. During the last 20 years, the unemployment rate has increased, accompanied by a reduction in the job finding rate and an increase in the separation rate. Also, the number of non-regular workers has continuously increased. It is known that these changes in the labor market are related to the demise of the "traditional Japanese employment system". Kato and Miyamoto (2013) also demonstrate that a structural change occurred in the Japanese labor market in the end of 1990s.

${ }^{7}$ We define the job finding rate as the rate of transition from unemployment to employment, and the separation rate as the rate of transition from employment to unemployment.
} 
seasonally adjusted by using the Census Bureau's X12 filter. To focus on cyclical fluctuations, we de-trend the logged data using Hodrick-Prescott (HP) filter with smoothing parameter 1,600. The sample covers the period 1980Q1-2009Q4.

Figure 6 displays the cyclical components of variables of interest and Table 1 summarizes key statistical moments. Figure 1 (a)-(b) and Table 1 show that the unemployment rate is counter-cyclical and the vacancy rate is pro-cyclical. The correlation between the unemployment rate and labor productivity is -0.57 . The correlation between the vacancy rate and labor productivity is 0.67 . Since the unemployment rate is countercyclical and the vacancy rate is procyclical, these two series co-move negatively. The correlation between them is -0.80 . The negative correlation between unemployment and vacancy, known as the Beveridge curve, can be also observed in Figure 1.

Both the unemployment rate and the vacancy rate are more volatile than labor productivity. While the standard deviation of labor productivity is 1.3 percent, the standard deviations of the unemployment and vacancy rates are 6.1 percent and 9.5 percent, respectively. Thus, the unemployment rate is about 4.5 times more volatile than labor productivity and the vacancy rate is about 7 times more volatile than labor productivity. The unemployment and vacancy rates exhibit large persistence with autocorrelation of 0.83 and 0.92 , respectively.

Figure 1 (c) and (d) show cyclical components of the job finding and separation rates. The job finding rate is pro-cyclical and the separation rate is counter-cyclical. The correlation between the job finding rate and labor productivity is 0.21 . The correlation between the separation rate and labor productivity is -0.48 . The standard deviations of job finding and separation rates are 8.1 percent and 8.7 percent, respectively. Similar to unemployment and vacancy rates, both job finding and separation rates fluctuates much more than labor productivity. Volatilities of these two series are roughly six times as large as that of labor productivity. The autocorrelation of the job finding rate is -0.11 , and that of the separation rate is 0.23 .

The real wage is procyclical. The correlation between the real wage and labor productivity is 0.5 . The standard deviation of the real wage is 1 percent, and thus the real wage fluctuates as much as labor productivity. The cyclical behavior of output is similar to that of labor productivity. The correlation between output and labor productivity is 0.952 . 


\section{The model}

We develop a discrete time search and matching model that we use as a data-generating process for the empirical analysis. The basic structure of the model follows Pissarides (2000) and some standard settings in the dynamic general equilibrium (DSGE) framework. In order to capture the importance of unemployment inflow channel in generating unemployment fluctuations, we incorporate a persistent shock to a separation rate. We also introduce a convex vacancy posting cost since it is known that the curvature of the vacancy posting cost affects the quantitative property of the search and matching model. Beside these two extensions, we also introduce a markup shock into our model. This is motivated by the finding in the recent literature that markup shocks largely accounts for labor market dynamics. ${ }^{8}$

The environment There are three types of agents in the economy: workers, firms, and retailers. Workers are identical, risk neutral and live forever. The number of total workers is normalized to one. A worker can be either employed or unemployed. If a worker is employed, he produces output and earns wages. If a worker is unemployed, he gets a flow utility from non-market activity and searches for a job.

Firms are identical, risk neutral and live forever. Firms recruit workers by posting vacancies. When firms employ workers, they produce homogeneous wholesale goods and sell them to retailers in a competitive market. Firms maximize their intertemporal profit functions by choosing the number of vacancies to be posted. Workers are separated from firms at a stochastic exogenous rate.

There exists a large number of symmetric retailers. Retailers buy wholesale goods and differentiate them to produce final goods. Final goods are sold in a monopolistic competitive market.

The labor market The labor market is subject to frictions and firms and workers cannot meet instantaneously but must go through a time-consuming search process. The number of successful job matches is determined by the Cobb-Douglas matching function,

$$
m\left(u_{t}, v_{t}\right)=m_{0} u_{t}^{\alpha} v_{t}^{1-\alpha},
$$

\footnotetext{
${ }^{8}$ See, for example, Smets and Wouters (2007), Justiniano et al. (2010) in the literature of the DSGE estimation, Rotemberg (2008) and Lubik (2009) in the literature of search and matching models.
} 
where $u_{t}$ is the number of unemployed workers, $v_{t}$ is the number of vacancies, $m_{0}$ represents the match efficiency and $0<\alpha<1$ is the elasticity of the matching function with respect to unemployment. Define $\theta_{t} \equiv v_{t} / u_{t}$, as the labor market tightness. The probability that a firm with a vacancy is matched with a worker is $m\left(u_{t}, v_{t}\right) / v_{t}=$ $m_{0} \theta_{t}^{-\alpha} \equiv q\left(\theta_{t}\right)$. Similarly, the probability that an unemployed worker is matched is $m\left(u_{t}, v_{t}\right) / u_{t}=m_{0} \theta_{t}^{1-\alpha}=\theta_{t} q\left(\theta_{t}\right)$. The number of employed workers is defined as

$$
n_{t}=1-u_{t}
$$

Matches are destroyed at an exogenous separation rate $s_{t}$, which takes place at the end of period $t$.

We assume that it takes one period for new matches to be productive and that both old and new matches face the same separation rate. The evolution of employed workers is given by

$$
n_{t}=\left(1-s_{t}\right)\left[n_{t-1}+m u_{t-1}^{\alpha} v_{t-1}^{1-\alpha}\right] .
$$

Thus, the number of employed workers at time $t$ is given by the number of employed workers at time $t-1$ plus new matches formed in period $t$ that were not destroyed.

Retailer's pricing rule Workers consume final goods produced by retailers. ${ }^{9}$ Instead of formally modeling a worker's consumption choice problem, we assume that the worker derives utility from consumption of a continuum of final goods aggregated using a Dixit-Stiglitz consumption index. Thus, the pricing rule in the retail sector is given by

$$
p_{t}=\frac{\epsilon_{t}}{\epsilon_{t}+1} p_{t}^{w}
$$

where $p_{t}$ is the price of final goods, $p_{t}^{w}$ is the price of wholesale goods, and $\epsilon_{t}$ is the elasticity of demand. Denote the price markup $\epsilon_{t} /\left(\epsilon_{t}+1\right)$ as $M_{t}$. Then, the relative wholesale goods price $p_{t}^{w} / p_{t}$ is given by $1 / M_{t}$.

Note that all retailers behave symmetrically and thus they charge an identical price. Let the consumption index constructed by final goods be numeraire. In the later discussion, the matching values, wages, unemployment benefits, and costs of posting vacancies, are measured in terms of consumption index of final goods.

\footnotetext{
${ }^{9}$ Allowing firms and retailers to focus on production decision and pricing decision, respectively, is common in the literature. This assumption reduces algebraic burden. See Bernanke et al. (1999), Walsh (2005) and Thomas (2008) for details.
} 
Firm's optimization Production takes place when a firm is matched with workers. Output $y_{t}$ of a typical firm is linear in employment $n_{t}$ :

$$
y_{t}=A_{t} n_{t}
$$

where $A_{t}$ is an aggregate productivity.

In order to hire workers, a firm has to post vacancies. The real cost of posting vacancies (in terms of final goods) is $\kappa v_{t}^{\phi} / \phi$ where $\kappa>0$ and $\phi>0 .{ }^{10}$ The firm pays workers real wages $w_{t}$, which will be derived below. The firm chooses the optimal number of vacancies $v_{t}$ to be posted and its employment level $n_{t}$ by maximizing the following inter-temporal profit function

$$
\mathbb{E}_{t} \sum_{t=0}^{\infty} \beta^{t}\left[\frac{A_{t} n_{t}}{M_{t}}-w_{t} n_{t}-\frac{\kappa}{\phi} v_{t}^{\phi}\right]
$$

subject to the equation of employment evolution (2). The first-order conditions are

$$
\begin{aligned}
\mu_{t} & =\frac{A_{t}}{M_{t}}-w_{t}+\beta \mathbb{E}_{t}\left[\mu_{t+1}\left(1-s_{t+1}\right)\right], \\
\frac{\kappa v_{t}^{\phi-1}}{q\left(\theta_{t}\right)} & =\beta \mathbb{E}_{t}\left[\mu_{t+1}\left(1-s_{t+1}\right)\right],
\end{aligned}
$$

where $\mu_{t}$ is the Lagrangian multiplier on constraint (2).

Making use of these two first-order conditions, we can obtain the job creation condition

$$
\frac{\kappa v_{t}^{\phi-1}}{q\left(\theta_{t}\right)}=\beta \mathbb{E}_{t}\left[\left(\frac{A_{t+1}}{M_{t+1}}-w_{t+1}+\frac{\kappa v_{t+1}^{\phi-1}}{q\left(\theta_{t+1}\right)}\right)\left(1-s_{t+1}\right)\right] .
$$

The job creation condition states that cost of posting a vacancy, the left-hand side of (3), is equal to the firm's share of the expected new surplus from a new job match, the right-hand side of (3).

Wage determination Wages are determined by Nash bargaining between a firm and a worker, where the worker has bargaining power $\eta \in(0,1)$. The surplus sharing implies

$$
(1-\eta)\left(W_{t}-U_{t}\right)=\eta J_{t}
$$

where $W_{t}$ is the value of an employed worker, $U_{t}$ is the value of an unemployed worker, and $J_{t}$ is the value of the marginal value of the worker to the firm.

\footnotetext{
${ }^{10}$ In the standard search and matching model, the cost of posting vacancies is assumed to be linear.
} 
The value of an employed worker is characterized by the following Bellman equation:

$$
W_{t}=w_{t}+\beta \mathbb{E}_{t}\left[\left(1-s_{t+1}\right) W_{t+1}+s_{t+1} U_{t+1}\right] .
$$

The value of $W_{t}$ is determined by several factors. In the current period, the worker receives wage $w_{t}$. In the next period, while the worker retains his job with probability $1-s_{t+1}$, he loses the job and becomes unemployed with probability $s_{t+1}$.

The value of an unemployed worker is

$$
U_{t}=b+\beta \mathbb{E}_{t}\left[\theta_{t} q\left(\theta_{t}\right)\left(1-s_{t+1}\right) W_{t+1}+\left(1-\theta_{t} q\left(\theta_{t}\right)\left(1-s_{t+1}\right)\right) U_{t+1}\right] .
$$

An unemployed worker receives unemployment benefits $b$ and transitions into employment with probability $\theta_{t} q\left(\theta_{t}\right)\left(1-s_{t+1}\right)$.

The value of the marginal worker to the firm $J_{t}$ is equivalent to the Lagrangian multiplier on employment constraint $\mu_{t}$, which is the shadow value of a filled job. Thus, the value of a filled job is

$$
J_{t}=\frac{A_{t}}{M_{t}}-w_{t}+\beta \mathbb{E}_{t}\left[J_{t+1}\left(1-s_{t+1}\right)\right] .
$$

By using the wage sharing rule (4), value functions (5), (6), (7), and the first-order conditions, we obtain the following wage equation

$$
w_{t}=\eta \frac{A_{t}}{M_{t}}+(1-\eta) b+\eta \theta_{t} \kappa v_{t}^{\phi-1} .
$$

By substituting (8) into (3), the job creation condition (3) can be rewritten as

$$
\frac{\kappa v_{t}^{\phi-1}}{q\left(\theta_{t}\right)}=\beta \mathbb{E}_{t}\left(1-s_{t+1}\right)\left[(1-\eta)\left(\frac{A_{t+1}}{M_{t+1}}-b\right)-\eta \theta_{t+1} \kappa v_{t+1}^{\phi-1}+\frac{\kappa v_{t+1}^{\phi-1}}{q\left(\theta_{t+1}\right)}\right] .
$$

The dynamics of the model are given by the three equations (1), (2), and (9) and the definition of the labor market tightness that solve for four unknowns $n_{t}, u_{t}, v_{t}$, and $\theta_{t}$.

Shocks There are three shocks in this model economy: the productivity shock $A_{t}$, the separation rate shock $s_{t}$, and the markup shock $\epsilon_{t}$. We assume that these shocks follow first-order autoregressive processes of the form:

$$
\log X_{t}=\left(1-\rho_{X}\right) \log X+\rho_{X} \log X_{t}+\varepsilon_{X, t}
$$

where $0<\rho_{X}<1, \varepsilon_{X, t} \sim N\left(0, \sigma_{X}^{2}\right)$ and $X=\{A, s, \epsilon\}$. Since labor productivity and the separation rate are negatively correlated in the data, we assume that the innovations of $A_{t}$ and $s_{t}$ are correlated. The correlation between two series is denoted by $\rho_{A, s}$. 


\section{Estimation}

The model is estimated by using Bayesian methods. First, we log-linearize the nonlinear model around a deterministic steady state. We then solve the model and apply the Kalman filter to evaluate the likelihood function of the observable variables. The likelihood function and the prior distribution of the parameters in the model are combined to obtain the posterior distribution. The posterior kernel is simulated numerically by employing the random-walk Metropolis-Hastings algorithm. ${ }^{11}$

To estimate the model, there should be at least as many sources of uncertainty in the empirical model as there are observables. For the benchmark specification, we use observations on two series: the unemployment rate $u$ and the vacancy rate $v$. We use these two series as observables since they are central variables in the search and matching model. Among three stochastic processes incorporated in the model, the productivity shock $A_{t}$ and the separation shock $s_{t}$ are selected as the exogenous unobservable stochastic process. Thus, the baseline case does not allow for variations in markup.

There are several reasons why we choose productivity and separation shocks as sources of variation in the empirical model. First, they are the fundamental exogenous shocks in the search and matching literature, while the markup shock has been criticized as non-structural shock in some studies (see for example, Chari et al., 2008). Second, since we obtain the data on labor productivity and the separation rate, we can further evaluate the performance of the model by comparing the estimated shock processes with the observed data. In an extension of the benchmark specification, we add the series of output $y$ and wages $w$ and the markup shock. ${ }^{12}$

In the following we first discuss the selection of the prior distributions. We then report the estimated parameters and evaluate the model's performance.

\subsection{Prior distribution and parameters}

In the baseline estimation, we use observations on the unemployment rate and the vacancy rate. The sample covers 1980Q1-2009Q4. We obtain these two series from the LFS and the monthly Report on Employment Service conducted by MHLW (please see Section 2 for the detail). All data are seasonally adjusted and de-trended using the HP

\footnotetext{
${ }^{11}$ Details on the estimation procedure can be found in An and Schorfheide (2007) and Lubik (2009).

${ }^{12}$ Although we have an information about stochastic processes of $A_{t}$ and $s_{t}$, it cannot be used in the estimation directly. The reason is that the information of exogenous shocks cannot help to identify parameters in the model structure, but parameters of shock processes.
} 
filter with smoothing parameter 1,600.

The model contains 9 structural parameters, excluding shock parameters. We choose priors for the Bayesian estimation based on the typical values in calibration studies. We set the discount rate $\beta=0.99$ because the annual real interest rate has been around $4 \%$. Elasticity of demand $\epsilon$ is set to be -10 . This implies that the steady state markup is 1.1, a conventional value in the literature. The remaining parameters are estimated. We use Beta distributions for parameters that take sensible values between zero and one, Gamma distributions for real-valued parameters, and the inverse Gamma distributions for the shock standard deviation.

The prior of the matching constant $m_{0}$ is chosen to be consistent with the observed job-finding rate of 0.142 per month (Miyamoto, 2011). Kano and Ohta (2002) estimate the matching function in the Japanese labor market by using aggregate data, and obtain the elasticity of the matching function $\alpha$ of about 0.6. We set $\alpha$ at a mean of 0.6 with a standard deviation of 0.15 . This leads to a prior mean of $m_{0}=0.15$. The prior mean of the separation rate $s$ is set to 0.012 , as estimated by Miyamoto (2011).

We now choose priors for the unemployment benefit $b$ and the worker's bargaining power $\eta \cdot{ }^{13}$ These two parameters have been the subject of some discussion in the literature. Martin (1998) computes the average replacement rates, the ratio of unemployment benefits to average wages, in the OECD countries and reports that the replacement rate in Japan is about 0.6 . We set $b$ at a mean of 0.6 with a wide coverage region. Regarding the worker's bargaining power, since we are interested in how much information on $\eta$ is in the data, we choose a uniform prior over the unit interval.

Regarding parameters in the vacancy cost function, the prior mean of the vacancy posting elasticity $\phi$ is set equal to 1 with a large standard deviation. A linear vacancy cost is the standard assumption in the literature. Then, the scale parameter is set to $\kappa=0.45$, which is obtained from the steady-state solutions of the model.

The prior mean of the autoregressive parameters is set equal to 0.5 and the prior mean of the standard deviations is set equal to 0.01 for all shocks. They are typical

\footnotetext{
${ }^{13}$ Much of the debate on the viability of the search and matching model as a description of the labor market centers around these parameter values. Shimer (2005) sets $b$ by targeting the replacement ratio of 0.4. Hagedorn and Manovskii (2008) argue that Shimer's choice of the value of the opportunity cost of employment is too low because it does not allow for the value of leisure, home production, or unemployment benefits. They calibrate the opportunity cost of employment and the worker's bargaining power to match the observed cyclical response of wages and average profit rate. Their results are $b=0.955$ and $\eta=0.052$. Mortensen and Nagypál (2007) criticize Hagedorn and Manovskii (2008) for using these parameters because these parameters yield workers a gain of $2.8 \%$ in flow utility by going from unemployment to employment.
} 
values used in the literature. The priors are summarized in columns 3-5 in Table 2.

\subsection{Posterior estimates of the parameters}

Table 2 (columns 6-7) reports posterior means together with their 90 percent confidence intervals. Figure 2 shows the prior and posterior distributions. In general, the parameter means and distributions are moved considerably from their priors, indicating the data are informative about the values of estimated parameters.

We begin by seeing the worker's bargaining power $\eta$ and the unemployment benefit $b$. The posterior means of the worker's bargaining power and the unemployment benefit are 0.376 and 0.861 , respectively. They are moved away considerably from the priors. These parameter estimates are in favor of Hagedorn and Manovskii (2008)'s calibrated parameter values. ${ }^{14}$

The posterior mean of the vacancy posting elasticity $\phi=3.627$ is considerably shifted away from the prior. The estimated $\phi$ suggests that vacancy creation is more costly to the firm because marginal vacancy posting costs are increasing in the number of vacancies. This estimate is substantially different from what is typically assumed in the calibration literature, that the vacancy cost function is linear $(\phi=1)$. The high value of $\phi$ may be interpreted as a balancing factor that mitigates excessive vacancy creation due to the low worker's bargaining power.

The estimates of the scale parameter $\mathcal{K}$ and the separation rate $s$ are not identified in a purely econometric sense, since the posterior distribution overlaps with the prior. This finding is consistent with $\operatorname{Lubik}(2009,2011)$. The posterior means of the match elasticity $\alpha$ is close to their prior means. The posterior mean of the match elasticity $\alpha=0.598$ is in the plausible range of 0.5-0.7 reported by Petrongolo and Pissarides (2001).

\subsection{Variance decompositions and impulse response functions}

We now compute variance decompositions to study sources of business cycles. The results are reported in Table 4 . In the baseline case, as shown in column (1), the productivity shock completely accounts for output and wage fluctuations. It also plays the dominant role in explaining fluctuations of unemployment and vacancies. However, it is important to note that the separation shock still explains $20 \%$ of the unemployment rate fluctuation. Since this number is non-trivial, this result can serve as the evi-

\footnotetext{
${ }^{14}$ In Hagedorn and Manovskii (2008), the value of an unemployment benefit is high and the value of a worker's bargaining power is low.
} 
dence that the separation rate shock significantly affects the unemployment dynamics in Japan.

Figure 3 plots impulse response functions of unemployment and vacancies to positive one-standard deviation shocks to productivity and the separation rate. They are computed at the posterior means of the structural parameters. On impact, a positive productivity shock leads to an increase in vacancies. A higher productivity level encourages firms to open more vacancies since it increases the expected return to hire a worker. Furthermore, the low worker's bargaining power implies that firms get a large part of the match surplus, leading to more vacancy creation. This leads to a persistent response of vacancy creation. Due to the timing assumption of the matching process, on the impact of the shock, unemployment does not respond and falls in the following periods.

Next, we consider the response of unemployment and vacancies to a separation shock. On impact, unemployment jumps up and then declines in the following periods. An increase in unemployed workers increases the number of job seekers. As a result, firms have higher incentives to create more vacancies. Thus, on the impact of a positive shock on the separation rate, vacancies increase and then decline in the following period since the number of unemployed workers fall.

\subsection{The model evaluation}

This section examines the quantitative performance of the benchmark model along several dimensions. We conduct simulations of the estimated model with parameters set at their posterior means. By comparing simulation results and counterpart data, we assess the ability of the model in accounting for the observed labor market dynamics. We also examine the properties of underlying shocks inferred through our estimation.

Table 5 reports various important statistics of simulation results and their data counterparts. In the baseline case, as shown in column (2), the model accounts for the volatility of the unemployment rate and the vacancy rate remarkably well. In the data, the standard deviations of the unemployment rate and the vacancy rate are 0.061 and 0.095 , respectively. The corresponding values implied by the model are 0.073 and 0.102 , respectively. The results imply that the search and matching model is a good datagenerating process for the unemployment and vacancy rates.

The model is successful in capturing a strong negative correlation between unemployment and vacancies, i.e. the Beveridge curve. Given the fact that the separation rate shock is negatively correlated to the productivity shock, this finding is important 
since it is well-known that search and matching models cannot generate the observed strong negative correlation between unemployment and vacancies when the separation rate is counter-cyclically moving in the model (see Fujita and Ramey (2012)).

In the calibration literature, the relative standard deviations of labor market variables to output are used to evaluate the quantitative performance of the search and matching model. The relative standard deviations of unemployment and vacancies to output in the data are 4.69 and 7.31, respectively. The corresponding values implied by the model are 0.74 and 1.03, respectively. These low values come from a counterfactually high output fluctuation. This is another manifestation of the Shimer puzzle in the sense that the volatilities of unemployment and vacancies relative to output volatility are too small. The results imply that the Shimer puzzle still holds under the parameter values supported by the full information of the data set.

We now examine whether the estimated shock processes are empirically plausible. To match the observed behavior of unemployment and vacancies, the model requires particular stochastic processes $\hat{A}_{t}$ and $\hat{s}_{t}$. They are treated as unobservable when the model is estimated. However, we can obtain the series on labor productivity and the separation rate from the data. ${ }^{15}$ Comparison between the cyclical properties of $\hat{A}_{t}$ and $\hat{s}_{t}$ in the data and those in the model is shown in Columns (1)-(2) of Table 5. While the volatility of $A_{t}$ in the model is about nine time as large as one in the data, the volatility of $s_{t}$ in the model is about half of one in the data. Furthermore, the correlation between $A_{t}$ and $s_{t}$ in the model is much weaker than one in the data.

These results are consistent with our earlier finding that the model requires a large productivity shock as the dominant source of fluctuations to capture the observed patterns of $u$ and $v$. However such large volatile $A_{t}$ also induces large fluctuations in $y_{t}$, which is not consistent with what we observe in the data. The discrepancy of $A_{t}$ and $s_{t}$ between in the model and in the data casts doubt on the ability of the benchmark model as description of labor market dynamics. This implies that in order to fix this problem, either some adjustment should be made in the model setting, or some other exogenous sources of shocks should be considered. We delve further into this issue in the next section.

\footnotetext{
${ }^{15}$ It is important to note that in the calibration literature, the shock processes are obtained directly from the observed series and examine if the model is capable of matching unemployment and vacancy volatilities.
} 


\section{Discussion}

In this section, we examine the quantitative performance of the search and matching model by changing model specifications and the choice of observables and shocks. We first explore the implications of non-linear vacancy costs and wage rigidity. We then assess the robustness of parameter estimates and the fit of the model to changes in the model specification and the choice of observables and shocks. Finally, we discuss what we can learn from estimating the search and matching model by using the Japanese data.

\subsection{Model modification - linear vacancy $\operatorname{cost} \phi=1$}

In the baseline case, we incorporate the convex vacancy posting cost, instead of the linear one commonly adopted in the literature. Now we assess the contribution of nonlinear vacancy costs to our results, by examining a model with linear vacancy costs. We set $\phi=1$ and re-estimate the model, given the priors of other parameters are fixed to the baseline case.

The results are reported in the third column of Table 3 and Column (3) of Table 5. Since the model with linear vacancy costs and the benchmark model use the same set of observables, we evaluate the overall fit of these models by comparing the marginal data densities (MDD). Table 5 shows that our benchmark specification is preferred with MDD of 474.3.

Except for the worker's bargaining power $\eta$, the posterior means are close to those in the baseline case. The posterior mean of the bargaining parameter $\eta=0.034$. Since the prior on this parameter is uniform, the shape of the posterior is exclusively determined by the data information. When the vacancy cost function becomes linear, it becomes less costly for a firm to open a vacancy. As a result, the volatility of $v$ is expected to be larger under the baseline parameter values. To mitigate the excess volatility of vacancies, the value of the worker's bargaining power is expected to rise. However, the value of $\eta$ becomes much smaller than the one in the baseline case. This seemingly counter-intuitive result can be understood, as follows: Given a linear vacancy cost and a low worker's bargaining power, a firm's surplus becomes larger. Thus, shocks have a lower influence on them. Thus, the low worker's bargaining power mitigates the excess volatility of vacancies caused by the linear vacancy cost. Indeed, our numerical analysis finds that if $\eta$ becomes less than a certain level, the firm's incentive to post a vacancy becomes 
weaker. ${ }^{16}$

The standard deviations of labor market variables of interest in the model with linear vacancy costs are broadly similar to those in the baseline case with the exception of wages. The standard deviation of wages in the model with linear vacancy costs is almost half of that in the baseline case. It is important to note that the standard deviation of output in the model with linear vacancy costs is slightly larger than that in the baseline case. As a result, the relative standard deviations of unemployment and vacancies to output in the model with $\phi=1$ are smaller than those in the baseline case.

We also find that the model with linear vacancy posting costs generates a strong negative correlation between unemployment and vacancies. This implies that the Beveridge curve found in the baseline case is caused by the convex vacancy posting cost.

\subsection{Model modification - wage rigidity}

A number of papers argue that an incorporation of wage rigidity improves the performance of a search and matching model to match the cyclical behavior of unemployment and vacancies (Hall, 2005; Shimer, 2005). We now assess whether an incorporation of wage rigidity improves the ability of our model to replicate the business cycle facts in the data.

Following Hall (2005) and Krause and Lubik (2007), we incorporate wage rigidity into our model in the form of a backward looking wage norm. Hall (2005) argues that a wage norm may arise from social convention that constrains wage adjustment. Without getting into the details of the wage norm, we assume that the actual wage is the weight average of a notional wage $w^{*}$ and a wage norm $w^{n}$ :

$$
w_{t}=\gamma w_{t}^{n}+(1-\gamma) w^{*}
$$

where $\gamma \in[0,1]$. We assume that the notional wage is equal to the bargaining solution of our benchmark model and the wage norm is the wage in the steady-state of the benchmark model. We assign the parameter $\gamma$ a Beta distribution with support on the unit interval. We set gamma at a mean of 0.5 with a wide coverage region. For other parameters, we use the prior specification in the baseline case.

The results are reported in columns labelled as wage rigidity in Tables 3, 5, and 4 . The posterior means are broadly similar to those in the baseline case with the exception

\footnotetext{
${ }^{16}$ Our numerical exercise finds that a relationship between $\eta$ and the volatility of vacancies $\sigma_{v}$ is not linear. There exists a threshold $\bar{\eta}$. When $\eta>\bar{\eta}, \sigma_{v}$ increases as $\eta$ decreases. On the other hand, when $\eta<\bar{\eta}, \sigma_{v}$ decreases as $\eta$ decreases.
} 
of the bargaining parameter $\eta$. The posterior mean of the worker's bargaining power is about 1.5 times as large as one in the baseline case. The estimated coefficient of wage rigidity $\gamma$ is 0.36 , with a $90 \%$ coverage interval $[0.10,0.61]$.

The relative standard deviations of $u$ and $v$ to output are 1.83 and 2.33, respectively. They are more than twice larger than those in the baseline case. However, they are still much lower than the observed volatility (about 39\% and 32\% of the observed volatility, respectively). The standard deviation of labor productivity series inferred through estimation dramatically decreases (about $1 / 3$ of the baseline case), but this value is still much larger than what we observed in the data.

These findings suggest that a sluggish wage determination mechanism provides a channel to amplify the effects of productivity shocks on unemployment and vacancy rates, as some recent studies suggested. However, it is not enough to solve the Shimer puzzle.

\subsection{Estimation with different sets of observables}

Let us suppose that the model could serve as a successful data-generating process for output and the unemployment rate (i.e. the model could generate "enough" relative volatility of unemployment to output), what are the parameter values supporting this hypothesis? and in the case, can model still well explain the labor market dynamics? To answer this question, we estimate our model using the data on the unemployment rate and output.

The results are reported in the columns labeled $\{u, y\}$ in Table 3, 4, and 5. In general the estimated parameters are similar to the baseline case, except the shock process. The model now requires less volatile productivity shock and and more volatile separation rate shock to generate the observed $y$ and $u$ sequences. And now, although the volatilities of vacancies and wages are smaller than the data, the model can generate empirically consistent prediction on volatilities of output and unemployment.

Apparently, much of this success, however, is due to the fact that the dynamics now is dominated by separation rate shocks. Note that, comparing to the baseline case, the relative standard deviation of the separation rate shock to productivity shock becomes around 9 times higher. This lead to the result, as shown in Table 4, that the labor market dynamics are exclusively captured by movements in the separation rate shock.

This kind of result implies several drawbacks. First, given that a positive separation rate shock leads to both positive movements in vacancy and unemployment rate, and that the economy is exclusively driven by the separation rate shock, the model cannot 
generate a negative relationship between unemployment and vacancies. That is, model cannot successfully match the Beveridge curve.

Second, it is counterintuitive that productivity shocks plays negligible role in the labor market dynamics. A more plausible explanations is that separation rate shock takes the role of a residual in the equation (2), the law of motion of unemployment; on the other hand, the productivity shock becomes the residual in the output equation. Therefore, the estimated results may simply reflect how these residuals related to the observables.

We also experiment with the estimations using $\{v, y\}$ and $\{u, w\}$ in place of $\{u, y\}$ as the observables. In all these cases, the models match the second moments reasonably well. All theses cases imply that the economy is driven by a much volatile $s_{t}$, exclusively explains the fluctuations of $u$ and $v$; and a less volatile $a_{t}$, exclusively explains the fluctuation of $y$ and $w$. Clearly, all these cases share the same drawbacks mentioned above.

\subsection{The model with a markup shock}

So far we have estimated the model with two conventional shocks, productivity and separation shocks, by using two observables. In an extension of the baseline empirical specification, we now add a price markup shock. We use two sets of observables: $\{u, v, w\}$ and $\{u, v, y\}$.

Results are reported in columns labelled " $u, v, w$ " and " $u, v, y$ " in Tables 3, 5, and 4. The parameter estimates are fairly consistent across specifications. The exception is the bargaining parameter $\eta$. In the estimation with observables $\{u, v, w\}$, the bargaining parameter $\eta$ is extremely low with the value of 0.108 . For both specifications, the model matches the data and second moments reasonably well. The key difference is driving forces of the business cycle. While unemployment and vacancies are mainly driven by the productivity shock in the estimation with $\{u, v, w\}$, they are mainly driven by the markup shock in the estimation with $\{u, v, y\}$.

The conclusion from the estimation using $\{u, v, y\}$, is similar to that drawn from the estimation using $\{u, y\}$ and $\{v, y\}$ : the fluctuations of labor markets, $\{u, v\}$, and the fluctuations of output are exclusively driven by different shocks. Since there is a strong connection between variables $\{u, v\}$ and $y$ imposed by model, the data generator (the model) are forced to let these two group of variables be explained by different shocks. The result is, the true relationship between model variables, described by model parameters, cannot truly recovered by observables. 
In contrast, the estimation results based on $\{u, v, w\}$ avoids this issue. After introducing the markup shocks, the connection between $w$ and $\{u . v\}$ is loosen, as it take the role of a residual in the wage determination equation. The estimation does not subject to a so tight constraint that observables need to be explained by different shock. Moreover, the estimated model can still generate similar prediction on the relative standard deviation of $u$ and $v$ to $y$, as the estimated model done by $\{u, v, y\}$.

Thus, we take the estimation based on $\{u, v, w\}$ as the representative case for the model with markup shock. Compare this with the baseline case, we find that their parameter estimates and the sources of business cycle fluctuations are rather similar. The newly introduced markup shock only accounts for the wage fluctuation. However, when model incorporate markup shocks, model's predictions on the output and wage fluctuation drastically improve. The ratio of standard deviations between $\{u, v\}$ and $y$ turns to be 5 times higher than the baseline case.

There are two significant differences between these two cases, while both related to wage determination: (1) when the markup shock introduced into the model, it directly influence the equilibrium wage (2) after introduce markup shocks, the worker's bargaining power $\eta$ becomes much smaller, while this smaller $\eta$ implies that the influence (the weight) of productivity and labor market tightness on wage becomes smaller. Both factors make the wage become less connect to the fundamentals ( $a$ and $\theta$ ). And as a result, we find the markup shock contributes nearly $40 \%$ of the wage fluctuations.

Thus, we could conclude that, once the tight relationship between wage and its fundamental are loosen, the model's explanatory power significantly improves.

\subsection{What we can learn about the Japanese labor market from estima- tion}

Our analysis shows that a simple search and matching model has difficulty in explaining Japanese labor market fluctuations through observed productivity and separation shocks. We find that the incorporation of wage rigidity, a promising solution to the Shimer puzzle in existing literature, provides an only limited improvement. However, we find that the incorporation of the markup shock significantly improves the model's ability to replicate the stylized facts over business cycles.

We now face an important question whether these findings are peculiar to the Japanese labor market. In order to answer the question, we repeat our exercise by using the U.S. data, and compare results from the U.S data with our own ones from the Japanese 
data. ${ }^{17}$ Table 6 reports several statistics of simulation results and their data counterparts in the U.S.

The estimation from the U.S. data leads to a completely different conclusion: the model misspecification, if any, could be reconciled by incorporating wage rigidity, instead of incorporating markup shocks. The relative standard deviations of unemployment and vacancies to output in the model with wage rigidity are about 4 times as large as those in the benchmark model. In contrast, the ratios in the model with markup shocks are about 1.15 times as large as those in the benchmark model. Furthermore, the correlation between $u$ and $y$ shows that the incorporation of markup shocks undermines the model's performance.

Our finding that the incorporation of wage rigidity does not help reconciling the search and matching model with the Japanese data so much, is consistent with what existing studies noted. It has been known that Japanese wages are more flexible than other industrial countries (Tachibanaki, 1991). The flexibility of wages in Japan is due to Japanese institutional factors such as annual synchronized wage bargaining (the Shunto), enterprise unions, and bonus payments.

While the incorporation of wage rigidity does not resolve the difficulty of the model in explaining the Japanese data, the incorporation of markup shocks does resolve it. Yet, what does the markup shock represent? Unfortunately, we are incapable to provide an unique explanation. This can be understood by seeing the linearized wage equation

$$
\hat{w}_{t}=f_{a} \hat{a}_{t}+f_{\theta} \hat{\theta}_{t}+f_{v} \hat{v}_{t}+\underbrace{g_{m} \hat{m}_{t}}_{e_{t}}
$$

where $f_{a}, f_{\theta}, f_{v}$ are functions of steady state variables, and variables with the "hat" represent their log-deviations from the steady state. The markup shock $g_{m} \hat{m}_{t}$ generates an exogenous uncertainty on the equilibrium wage. If we now replace this markup shock by introducing a "bargaining power shock", the above equation (10) can be rewritten as

$$
\hat{w}_{t}=f_{a} \hat{a}_{t}+f_{\theta} \hat{\theta}_{t}+f_{v} \hat{v}_{t}+\underbrace{g_{\eta} \hat{\eta}_{t}}_{e_{t}} .
$$

The term $g_{\eta} \hat{\eta}_{t}$ is mathematically equivalent to the $g_{m} \hat{m}_{t}$ in equation (10), but their underlying meanings are different. This implies that, as long as a stochastic term $e_{t}$, regardless

\footnotetext{
${ }^{17}$ For the estimation, we use observations on the unemployment rate, the vacancy rate, output, and wages in the U.S. The sample period covers 1980Q1-2009Q2, the same time span as the Japanese data we use. The selection of priors mostly follows the values in the literature, except for $m_{0}$ and $\kappa$, whose values are calibrated by targeting the job-finding rate of $0.7(\operatorname{Lubik}(2009))$ and $\theta^{*}=1.02$ (calculated from the data). Following Shimer(2005), we set the prior means of $\eta=0.5$, the separation rate $=10 \%$, and $\alpha=0.7$.
} 
of its economic meaning, is incorporated into the wage equation, this $e_{t}$ could achieve what the markup shocks does. ${ }^{18}$

Although it is hard to exactly identify what the markup shock represents, our finding implies that Japanese wages are largely influenced by some factors other than fundamentals in the labor market. Such factors may arise from fluctuations in the elasticity of substitution across different types of goods (price markup shocks) or labor (wage markup shocks), and account for about $52 \%$ of the wage fluctuation. This finding is supported by existing studies. For example, Sugo and Ueda (2007) estimate a medium size DSGE model by using the Japanese data, and find that both price and wage markup shocks account for about $78.8 \%$ of the wage fluctuations at one quarter, while the productivity shock only accounts for about $12.9 \%$. These two numbers are similar to what we obtain from our model. On quarterly basis, the contributions of markup and productivity shocks are $90.3 \%$. 9.7\%, respectively.

Equally important, we find that the separation rate shock plays a more important role in accounting for the unemployment rate fluctuations in Japan than in the U.S. Our quantitative analysis shows that both in baseline case and the case with markup shocks, the contribution of separation rate shocks to unemployment fluctuations in Japan is about $20 \%$. This is twice as much as what we find by using the U.S. data. This result is consistent with several empirical studies. Recently, a number of studies document that the contribution of job separation to unemployment fluctuations in Japan is larger than that in the U.S (see, for example, Shimer (2012), Miyamoto (2011), Lin and Miyamoto (2012)).

\section{Conclusion}

This paper studies how well a search and matching model describes aggregate Japanese labor market dynamics in a full information setting. We develop a simple search and matching model with a convex vacancy posting cost and three shocks: productivity, separation, and markup shocks. We use the model as a data-generating process for our empirical analysis, and estimate it using Bayesian methods. By taking into account all moments of the data and not just selected covariates, we come up with a structural estimation of the model that allows us to study the ability of the model to describe labor market dynamics. To the best of our knowledge, this is the first paper to study the Japanese labor market from the perspective of the structural estimation of the search

\footnotetext{
${ }^{18}$ This $e_{t}$ can also link to shocks on unemployment benefit $b$ or the disutility of labor supply.
} 
and matching model.

The model replicates the behavior of unemployment and vacancies in Japan remarkably well. Specifically, the model is capable of replicating the observed high volatility of unemployment and vacancies, and the negative relationship between them. However, we also find that there exists a certain discrepancy between the shock processes inferred through the estimation process and their empirical counterparts. Introducing either wage rigidity or the markup shock to the model can alleviate this issue. The former has less effects when applied to the Japanese labor market. This supports the claim that the wage is in general more flexible in Japan, as suggested in the existing literature. Though the markup shock plays an important role in not only improving the model's explanatory power but also accounting for the wage fluctuations, it is still unclear what it represents. Exploring this issue remains for future research.

\section{References}

[1] An, S., Schorfheide, F., 2007. Bayesian Analysis of DSGE Models. Econometric Reviews, 26(2-4), 113-172.

[2] Bernanke, B., Gertler, S., Gilchrist, S., 1999. The financial accelerator in a quantitative business cycle framework, in Handbook of Macroeconomics, volume 1 (Eds) J. B. Taylor and M. Woodford, pp.1341-1393,

[3] Chari, V., Kehoe, P., McGrattan, E., 2009. New Keynesian Models: Not Yet Useful for Policy Analysis. American Economic Journal: Macroeconomics 1(1), 242-266.

[4] Esteban-Pretel, J., Fujimoto, J., 2012. Life-cycle search, match quality and Japan's labor market. Journal of The Japanese and International Economies 26(3), 326-350.

[5] Esteban-Pretel, J., Nakajima, R., Tanaka, R., 2011. Japan's Labor Market Cyclicality and the Volatility Puzzle. Graduate Institute for Policy Studies, Mimeo.

[6] Fujita, S., Ramey G., 2007. Job matching and propagation. Journal of Economic Dynamics and Control, Elsevier, Vol. 31(11), 3671-3698.

[7] Fujita, S., Ramey G., 2012. Exogenous versus Endogenous Separation. American Economic Journal: Macroeconomics, American Economic Association, Vol. 4(4), 68-93. 
[8] Hagedorn, M., Manovskii, I., 2008. The cyclical behavior of equilibrium unemployment and vacancies revisited. American Economic Review 98 (4), 1692-1706.

[9] Hall, R.E., 2005. Employment Fluctuations with Equilibrium Wage Stickiness. American Economic Review 95(1), 50-65.

[10] Hashimoto, M., 1990. Introduction to the Japanese Labor Market in a Comparative Perspective with the United States. W.E. Upjohn Institute for Employment Research, 1-11.

[11] Hornstein, A., Krusell, P., Violante, G., 2005. Unemployment and Vacancy Fluctuations in the Matching Model: Inspecting the Mechanism. Economic Quarterly (Federal Reserve Bank of Richmond), Vol. 91(3), 19-51.

[12] Justiniano, A., Primiceri, G.E. \& Tambalotti, A., 2010. Investment shocks and business cycles. Journal of Monetary Economics, 57(2), pp.132-145.

[13] Kano, S., Ohta, M., 2002. An empirical matching function with regime switching: the Japanese case. Discussion Paper No. 967, Institute of Policy and Planning Sciences, University of Tsukuba, Tsukuba, Japan.

[14] Kato, R.R., Miyamoto, H., 2013. Fiscal stimulus and labor market dynamics in Japan. Journal of The Japanese and International Economies 30, 33-58.

[15] Krause, M. U., Lubik, T. A., 2007. The irrelevance of real wage rigidity in the New Keynesian model with search frictions. Journal of Monetary Economics 54(3), 706727.

[16] Lin, C.-Y., Miyamoto, H., 2012. Gross Worker Flows and Unemployment Dynamics in Japan. Journal of The Japanese and International Economies 26(1), 44-61.

[17] Lubik, T. A., 2009. Estimating a Search and Matching Model of Aggregate Labor Market. Economic Quarterly 95(2), 101-120.

[18] Lubik, T. A., 2011. Aggregate labor market dynamics in Hong Kong. Pacific Economic Review (forthcoming).

[19] Martin, J.P., 1998. What works among active labour market policies: evidence from OECD countries' experiences. OECD Labour Market and Social Policy-Occasional Papers No.35. 
[20] Miyamoto, H., 2011. Cyclical behavior of unemployment and job vacancies in Japan. Japan and the World Economy 23, 214-225.

[21] Miyamoto, H., Shirai, Y. 2006. Job Flows and Unemployment in an Equilibrium Unemployment Model with Firm-Specific Skill Training. The Japanese Economic Review 57(4), 547-561.

[22] Mortensen, D.T., Nagypál, E., 2007. More on unemployment and vacancy fluctuations. Review of Economic Dynamics 10(3), 327-347.

[23] Petrongolo, B., Pissarides, C., 2001. Looking Into the Black Box: A Survey of the Matching Function. Journal of Economic Literature, 39, 390-431.

[24] Pissarides, C.A., 2000. Equilibrium Unemployment Theory, 2nd ed. MIT Press, Cambridge, MA.

[25] Rotemberg, J, J., 2008. Cyclical Wages in a Search-and-Bargaining Model with Large Firms. In NBER International Seminar on Macroeconomics 2006. Chicago: University of Chicago Press, 65-114.

[26] Shimer, R., 2005. The cyclical behavior of unemployment and vacancies: evidence and theory. American Economic Review 95, 25-49.

[27] Shimer, R., 2012. Reassessing the ins and outs of unemployment. Review of Economics Dynamics 15, 127-148.

[28] Smets, F., Wouters, R., 2007. Shocks and Frictions in US Business Cycles: A Bayesian DSGE Approach. The American Economic Review, 97(3), 586-606.

[29] Sugo, T. \& Ueda, K., 2007. Estimating a dynamic stochastic general equilibrium model for Japan. Journal of the Japanese and International Economies 22, 476-502.

[30] Tachibanaki,T., 1991. Labour Market Flexibility in Japan in Comparison with Europe and the U.S, NBER Chapters, In International Volatility and Economic Growth: The First Ten Years of The International Seminar on Macroeconomics, National Bureau of Economic Research, Inc. 1991, 115-152.

[31] Tawara, N., 2011. The ins and outs of cyclical unemployment in Japan. Kantogakuen University, Mimeo. 
[32] Thomas, C., 2008. Search and matching frictions and optimal monetary policy. Journal of Monetary Economics, 55(5), 936-956.

[33] Walsh, C., 2005. Labor market search, sticky prices, and interest rate policies. Review of Economic Dynamics, 8(4), 829-849.

[34] Yahiv, E., 2006. Evaluating the Performance of the Search and Matching Model. European Economic Review, 95, 909-936. 
Table 1: Summary statistics, quarterly Japanese data, 1980-2009

\begin{tabular}{lcccccccc}
\hline & $u$ & $v$ & $f$ & $s$ & $w$ & $y$ & $A$ \\
\hline Standard deviation & & 0.061 & 0.095 & 0.081 & 0.087 & 0.010 & 0.015 & 0.013 \\
Autocorrelation & & 0.825 & 0.920 & -0.107 & 0.235 & 0.592 & 0.764 & 0.659 \\
\hline Correlation matrix & $u$ & 1 & -0.804 & -0.468 & 0.537 & -0.451 & -0.735 & -0.572 \\
& $v$ & - & 1 & 0.405 & -0.577 & 0.628 & 0.765 & 0.666 \\
& $f$ & - & - & 1 & -0.458 & 0.220 & 0.293 & 0.207 \\
& $s$ & - & - & - & 1 & -0.384 & -0.515 & -0.484 \\
& $w$ & - & - & - & - & 1 & 0.547 & 0.501 \\
& $y$ & - & - & - & - & - & 1 & 0.952 \\
& $A$ & - & - & - & - & - & - & 1
\end{tabular}

Note: The unemployment rate $u$ is constructed from the LFS. The vacancy rate $v$ is constructed from Employment Security Service Statistics. The job-finding rate $f$ and the separation rate $s$ are constructed from the LFS. See the text for data construction details. $u, v, f$, and $s$ are quarterly averages of monthly series. Real wages $w$ are taken from MLS. The output series $y$ is real GDP in per capita term. Labor productivity $A$ is measured as real output per employed workers. I seasonally adjust all series using the Census's X-12-ARIMA algorithm. All variables are reported in logs as deviations from an HP trend with smoothing parameter 1600. Sample covers 1980Q1-2009Q4. 
Table 2: Parameter estimates

\begin{tabular}{|c|c|c|c|c|c|c|}
\hline \multirow[t]{2}{*}{ Parameter } & \multirow[t]{2}{*}{ Description } & \multirow[b]{2}{*}{ Density } & \multicolumn{2}{|c|}{ rior } & \multicolumn{2}{|c|}{ Posterior } \\
\hline & & & Mean & Std. Dev. & Mean & 90 Percent Interval \\
\hline$\beta$ & Discount rate & Fixed & 0.99 & - & & \\
\hline$\epsilon$ & Elasticity of demand & Fixed & -10 & - & & \\
\hline$\alpha$ & Match elasticity & Beta & 0.60 & 0.15 & 0.598 & {$[0.549,0.644]$} \\
\hline$m_{0}$ & Match efficiency & Gamma & 0.15 & 0.05 & 0.217 & {$[0.161,0.272]$} \\
\hline$s$ & Separation rate & Beta & 0.012 & 0.002 & 0.011 & {$[0.008,0.014]$} \\
\hline$\eta$ & Worker's bargaining power & Uniform & 0.50 & 0.25 & 0.376 & {$[0.001,0.743]$} \\
\hline$b$ & Unemployment benefit & Beta & 0.60 & 0.2 & 0.861 & {$[0.707,0.994]$} \\
\hline$\phi$ & Elasticity of vacancy creation & Gamma & 1.0 & 0.50 & 3.627 & {$[2.749,4.532]$} \\
\hline$\kappa$ & Scaling factor on vacancy creation & Gamma & 0.45 & 0.10 & 0.459 & {$[0.307,0.617]$} \\
\hline$\rho_{A}$ & AR-coefficients of shocks & Beta & 0.50 & 0.20 & 0.934 & {$[0.895,0.973]$} \\
\hline$\rho_{s}$ & AR-coefficients of shocks & Beta & 0.50 & 0.20 & 0.144 & {$[0.018,0.266]$} \\
\hline$\sigma_{A}$ & Standard deviation of shocks & Inverse Gamma & 0.01 & 1.00 & 0.035 & {$[0.005,0.070]$} \\
\hline$\sigma_{s}$ & Standard deviation of shocks & Inverse Gamma & 0.01 & 1.00 & 0.038 & {$[0.025,0.051]$} \\
\hline$\rho_{A, s}$ & Correlation between shocks & uniform & -0.5 & 0.29 & -0.155 & {$[-0.301,0.000]$} \\
\hline
\end{tabular}


Table 3: Parameter estimates: posterior mean

\begin{tabular}{lllllllll}
\hline Case & Baseline & $\phi=1$ & Wage Rigidity & $u, v, w$ & $u, v, y$ & $u, y$ & $v, y$ & $u, w$ \\
\hline$\alpha$ & 0.598 & 0.594 & 0.596 & 0.585 & 0.595 & 0.495 & 0.699 & 0.520 \\
$m_{0}$ & 0.217 & 0.231 & 0.223 & 0.228 & 0.249 & 0.189 & 0.180 & 0.184 \\
$\mathcal{S}$ & 0.011 & 0.012 & 0.012 & 0.014 & 0.013 & 0.012 & 0.010 & 0.011 \\
$\eta$ & 0.376 & 0.034 & 0.576 & 0.108 & 0.510 & 0.221 & 0.185 & 0.645 \\
$b$ & 0.861 & 0.595 & 0.798 & 0.985 & 0.897 & 0.694 & 0.342 & 0.616 \\
$\phi$ & 3.627 & - & 3.841 & 3.233 & 4.151 & 1.344 & 1.052 & 1.888 \\
$\kappa$ & 0.459 & 0.422 & 0.383 & 0.495 & - & 0.522 & 0.476 & 0.427 \\
$\rho_{A}$ & 0.934 & 0.935 & 0.931 & 0.944 & 0.756 & 0.648 & 0.757 & 0.542 \\
$\rho_{s}$ & 0.144 & 0.129 & 0.148 & 0.107 & 0.189 & 0.271 & 0.764 & 0.310 \\
$\sigma_{A}$ & 0.035 & 0.042 & 0.012 & 0.005 & 0.010 & 0.010 & 0.010 & 0.012 \\
$\sigma_{s}$ & 0.038 & 0.037 & 0.038 & 0.045 & 0.033 & 0.114 & 0.079 & 0.102 \\
$\rho_{A, s}$ & -0.155 & -0.071 & -0.143 & -0.222 & -0.080 & -0.184 & -0.018 & -0.336 \\
$\gamma$ & - & - & 0.359 & - & - & - & - & - \\
$\rho_{\epsilon}$ & - & - & - & 0.390 & 0.927 & - & - & - \\
$\sigma_{\epsilon}$ & - & - & - & 0.736 & 0.361 & - & - & - \\
\hline & & & & & & &
\end{tabular}

\section{Table 4: Variance decompositions}

\begin{tabular}{lllllllll}
\hline Case & $(1)$ Baseline & $(2) \phi=1$ & $(3)$ Wage Rigidity & $(4) u, v, w$ & $(5) u, v, y$ & $(6) u, y$ & $(7) v, y$ & $(8) u, w$ \\
& {$[a, s]$} & {$[a, s]$} & {$[a, s]$} & {$[a, s, \epsilon]$} & {$[a, s, \epsilon]$} & {$[a, s]$} & {$[a, s]$} & {$[a, s]$} \\
\hline$u$ & {$[79.5,20.5]$} & {$[84.4,15.6]$} & {$[68.8,31.2]$} & {$[78.6,21.3,0.1]$} & {$[1.5,25.2,73.3]$} & {$[4.8,95.2]$} & {$[0.1,99.9]$} & {$[8.9,91.1]$} \\
$v$ & {$[99.5,0.5]$} & {$[93.6,6.4]$} & {$[99.3,0.7]$} & {$[99.0,0.6,0.4]$} & {$[1.3,0.5,98.2]$} & {$[2.9,97.1]$} & {$[0.3,99.7]$} & {$[6.2,93.8]$} \\
$y$ & {$[100.0,0.0]$} & {$[100.0,0.0]$} & {$[100.0,0.0]$} & {$[99.7,0.3,0.0]$} & {$[99.5,0.1,0.4]$} & {$[97.0,3.0]$} & {$[96.2,3.8]$} & {$[98.0,2.0]$} \\
$w$ & {$[100.0,0.0]$} & {$[100.0,0.0]$} & {$[100.0,0.0]$} & {$[48.1,0.0,51.9]$} & {$[59.8,0.4,39.8]$} & {$[79.8,20.2]$} & {$[86.1,13.9]$} & {$[95.1,4.9]$} \\
\hline
\end{tabular}


Table 5: Data and model fit

\begin{tabular}{lrrrrrrrrr}
\hline & Data & Baseline & $\phi=1$ & Wage Rigidity & $u, v, w$ & $u, v, y$ & $u, y$ & $v, y$ & $u, w$ \\
& $(1)$ & $(2)$ & $(3)$ & $(4)$ & $(5)$ & $(6)$ & $(7)$ & $(8)$ & $(9)$ \\
\hline Marginal Likelihood & & 474.276 & 429.036 & 475.635 & & & & & \\
$\sigma(u)$ & 0.061 & 0.073 & 0.070 & 0.060 & 0.074 & 0.064 & 0.073 & 0.093 & 0.071 \\
$\sigma(v)$ & 0.095 & 0.102 & 0.109 & 0.077 & 0.097 & 0.089 & 0.046 & 0.085 & 0.032 \\
$\sigma(w)$ & 0.010 & 0.083 & 0.046 & 0.023 & 0.012 & 0.015 & 0.006 & 0.006 & 0.011 \\
$\sigma(y)$ & 0.015 & 0.099 & 0.118 & 0.033 & 0.017 & 0.015 & 0.014 & 0.016 & 0.015 \\
$\sigma(a)$ & 0.013 & 0.098 & 0.117 & 0.032 & 0.015 & 0.015 & 0.013 & 0.016 & 0.015 \\
$\sigma(s)$ & 0.087 & 0.039 & 0.037 & 0.038 & 0.046 & 0.034 & 0.119 & 0.122 & 0.107 \\
$\rho(u, v)$ & -0.800 & -0.850 & -0.800 & -0.800 & -0.840 & -0.810 & 0.820 & 0.940 & 0.880 \\
$\rho(a, s)$ & -0.480 & -0.060 & -0.030 & -0.060 & -0.080 & -0.060 & -0.160 & -0.020 & -0.270 \\
$\sigma(u) / \sigma(y)$ & 4.69 & 0.74 & 0.59 & 1.83 & 4.41 & 4.21 & 5.43 & 5.73 & 4.61 \\
$\sigma(v) / \sigma(y)$ & 7.31 & 1.03 & 0.92 & 2.33 & 5.79 & 5.84 & 3.39 & 5.22 & 2.07 \\
$\sigma(w) / \sigma(y)$ & 0.67 & 0.84 & 0.39 & 0.69 & 0.69 & 0.98 & 0.41 & 0.40 & 0.69 \\
\hline
\end{tabular}

Table 6: The U.S. data and model predictions

\begin{tabular}{lrrrr}
\hline & Data & Baseline & Wage Rigidity & $u, v, w$ \\
& $(1)$ & $(2)$ & $(3)$ & $(4)$ \\
\hline$\rho(u, v)$ & -0.90 & -0.90 & -0.90 & -0.63 \\
$\sigma(u) / \sigma(y)$ & 7.89 & 0.55 & 2.11 & 0.64 \\
$\sigma(v) / \sigma(y)$ & 9.05 & 0.64 & 2.45 & 0.73 \\
$\sigma(w) / \sigma(y)$ & 0.79 & 0.89 & 1.74 & 0.12 \\
\hline
\end{tabular}


(a)

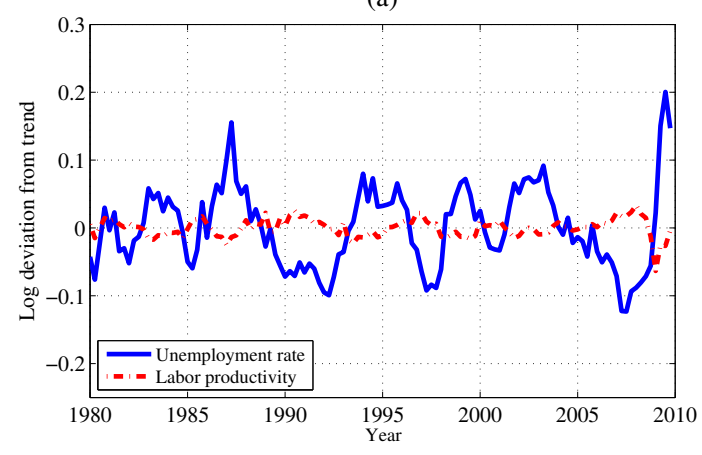

(c)

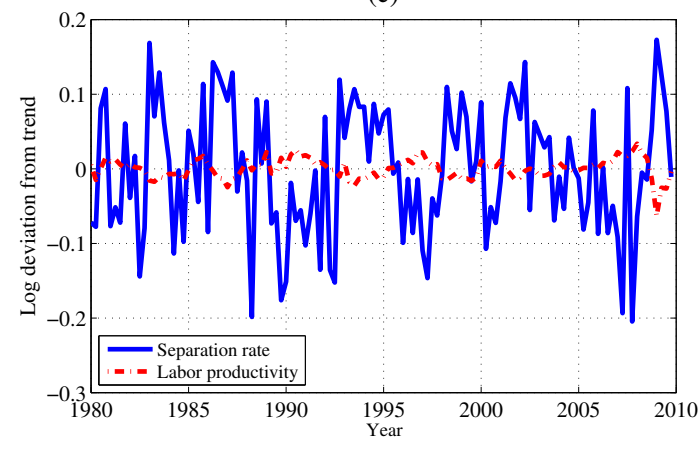

(e)

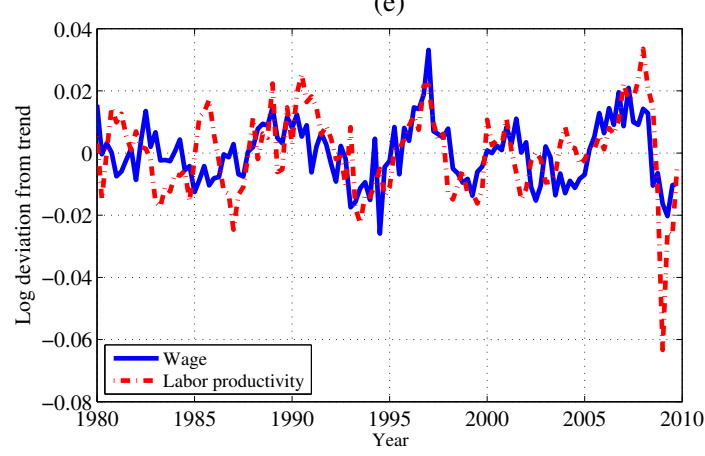

(b)

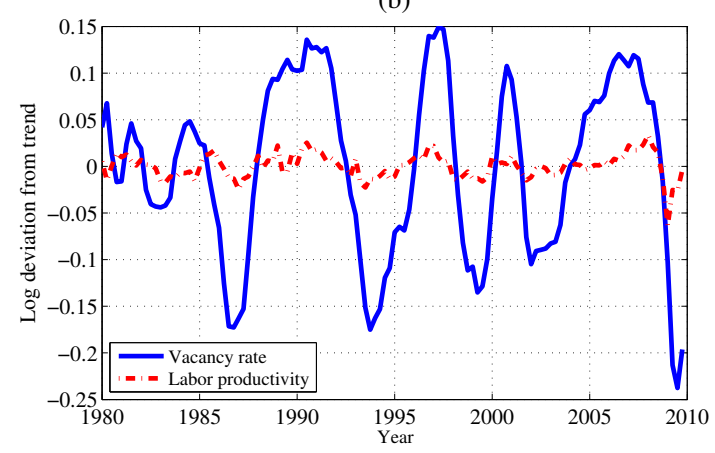

(d)

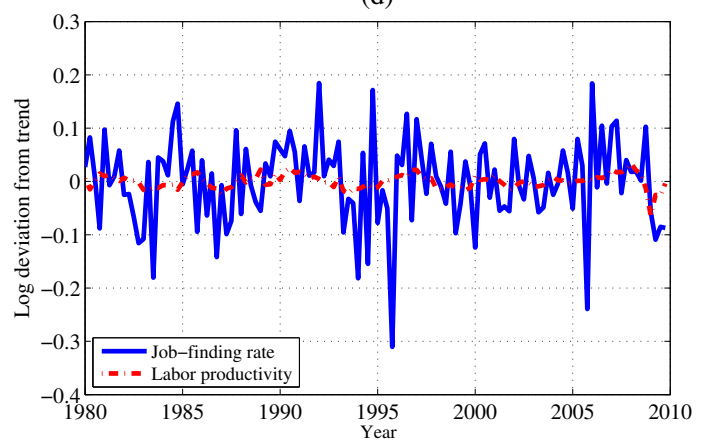

(f)

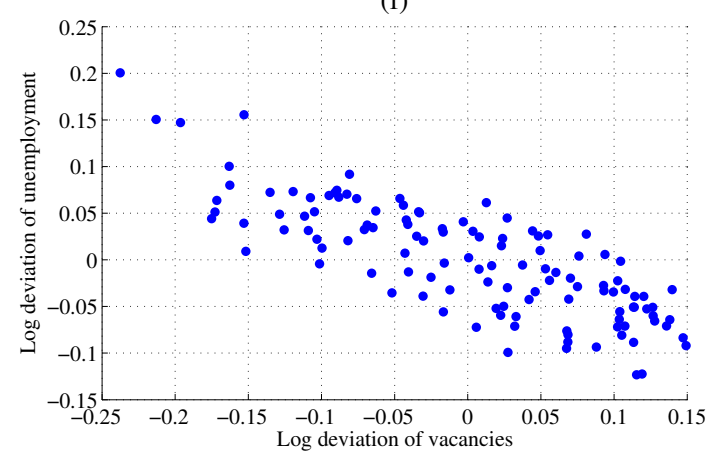

Figure 1: cyclical behavior of indicators in labor market

Note: The dashed line indicates the cyclical component of labor productivity. The solid lines indicate the cyclical components of the unemployment rate, the vacancy rate, the job-finding rate, and the separation rate. All series are reported in logs as deviations from the HP trend with smoothing parameter 1600. Sample covers 1980Q1-2009Q4. 

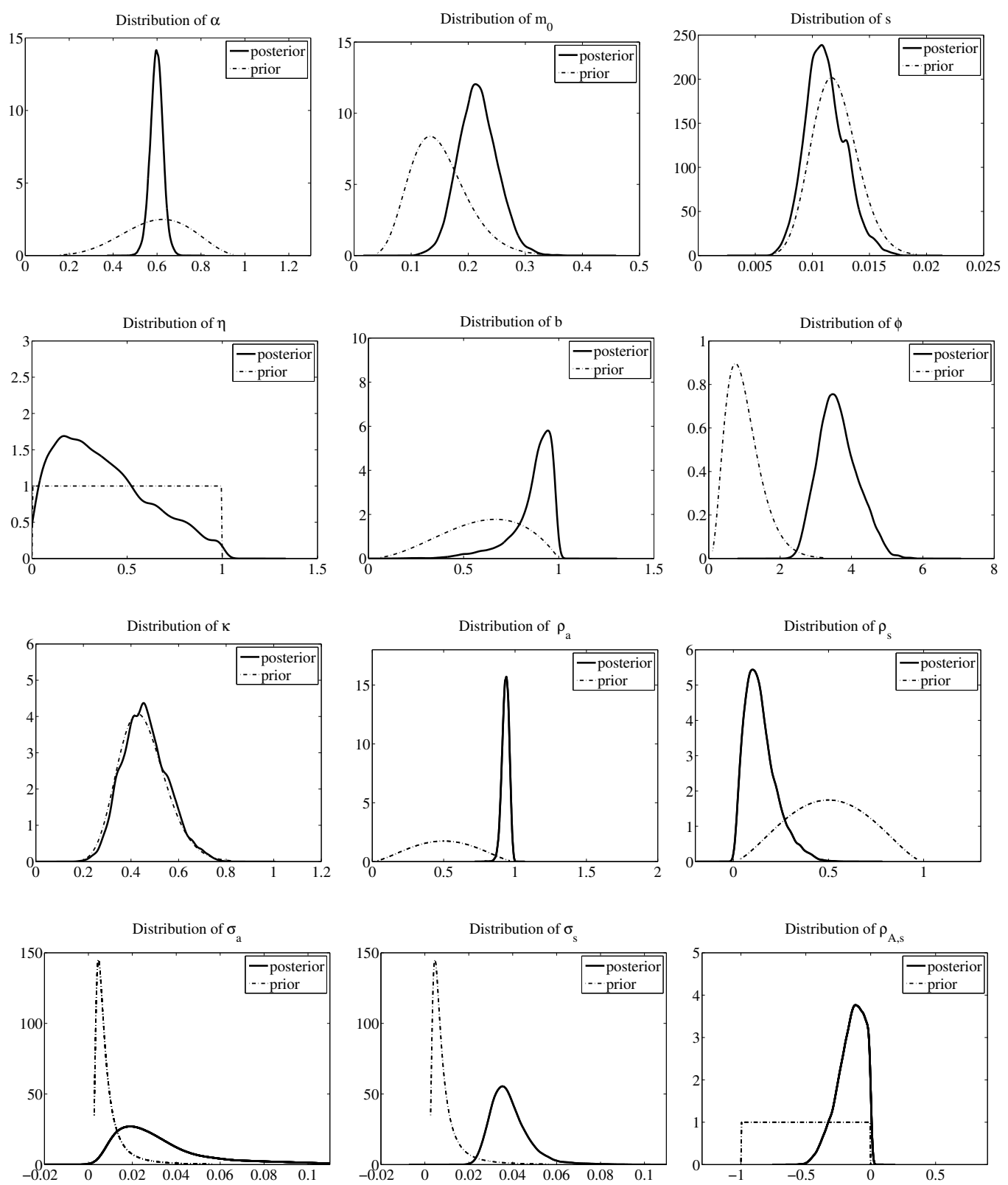

Figure 2: Prior and posterior distribution 

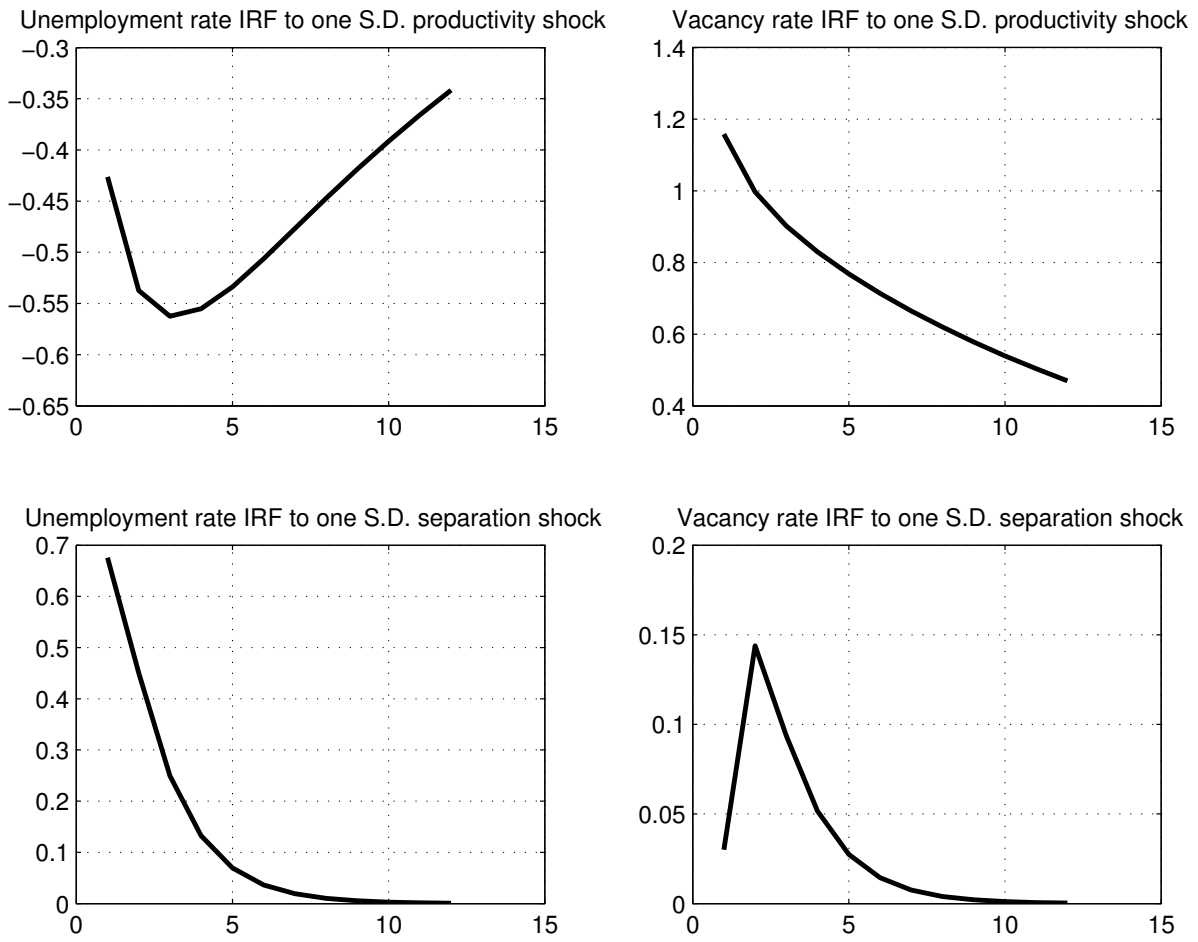

Figure 3: Impulse responses to productivity and separation shocks 